\title{
Family contact in foster care in Portugal. The views of children in foster care and other key actors
}

\author{
Paulo Delgado ${ }^{1}$ | | Vânia S. Pinto ${ }^{2}$ | João M.S. Carvalho ${ }^{3}$ | Robbie Gilligan ${ }^{4}$
}

${ }^{1}$ InED, Escola Superior de Educação do Porto/ CIEC, Universidade do Minho, Porto, Portugal

${ }^{2}$ InED, REES Centre, Department of

Education, University of Oxford, Oxford, UK

${ }^{3}$ CICS.NOVA.UMinho, InED-ESE-IPP,

UNICES-Instituto Universitário da Maia, Porto, Portugal

${ }^{4}$ School of Social Work and Social Policy, Trinity College Dublin, Dublin, Ireland

Correspondence

Paulo Delgado, InED, Escola Superior de Educação do Porto/CIEC, Universidade do Minho, Porto, Portugal.

Email: pdelgado@ese.ipp.pt

\begin{abstract}
This is a pilot study on the sensitive issue of how children and young people experience family contact in foster care, and the views of key adults in their lives on the same issue. There is a special focus on the children's experiences, opinions, and feelings. The study is a response to the relative scarcity of literature on family contact based on the experiences of children and adults in caring roles. This is a qualitative and exploratory study, with a sample of 10 children and young people in care in the district of Porto, aiming to identify key issues and areas for further examination. The results allow us to conclude that the possibility of maintaining contact is positively evaluated. However, perspectives on the relationships involved, and on the reactions to and difficulties associated with visits, revealed considerable disagreement among the actors. A possible set of implications drawn from the findings pointed out to the importance of developing a monitored cooperation that improves communication processes in order to take into account the children's and young people's views in the decision-making process; and to develop more attentive and open working relationships with parents throughout the foster care placement.
\end{abstract}

\section{KEYWORDS}

child care, children's and young people's views, family contact, foster care

\section{1 | CONTACT IMPORTANCE AND CHALLENGES}

Recent literature suggests that when contact is positive, it produces beneficial effects on the child or young person, such as the strengthening of physical and genealogical identity; a feeling of greater tranquillity, because the child or young person feels that the parents are well and that they care for them; a decrease in anxiety and feelings of guilt; the demonstration of love and affection; the reduction of feelings of loss and rejection; and the promotion of self-esteem (Delgado et al., 2016; Triseliotis, 2010).

However, such family contact may not be an easy process. Some of the difficulties associated with the contact in foster or residential care are due to the fact that there are several actors involved, as well as a mixture of different feelings, such as hostility, affection, loyalty, ambivalence, conflict, disqualification, or nostalgia, which might lead to cooperative behaviours or rivalries and misunderstandings (Carvalho \& Delgado, 2014).

Although there is a growing literature on family contact issues for children in care, research based on cases drawing on the actual experiences of children and adults in caring roles is still relatively scarce.

Maintaining contact with parents, other family members, or reference people is crucial for children and young people in care for several reasons. First, from an ethical point of view, contact is an essential right of people that are separated, in accordance with the current legal framework, namely, the Convention on the Rights of the Child. Second, contact can lessen the impact of change that occurs in children and young people's life when they are placed in care, maintaining a connection with their past and identity, and avoiding the disappearance of the relationships and emotional capital that they brought into this transition (Coakley, 2013; McWey, Acock, \& Porter, 2010). Third, because the child or young person when newly placed often strongly 
seeks reunification with their parents, keeping contact alive can promote the maintenance of the relationships during this period. Therefore, contact is essential for the maintenance of family ties, contributing to the well-being of the child or young person and to the future of the relationship with their parents (Fawley-King, Zhang, Aarons, \& A, 2017; McWey, 2000).

According to Sen and Broadhurst (2011) and HÖjer (2011), good quality contact with the family of origin combined with support from the social work team is associated with positive outcomes for children and young people, particularly in terms of placement stability and successful family reunification (Vanderfaeillie, Van Holen, \& Coussens, 2008). On the other hand, Moyers, Farmer, and Lipscombe (2006) stress that contact does not always happen as planned, because the family of origin sometimes arrives late or misses the visit. The same authors also mention that contact can sometimes be harmful for the children and young people because the family of origin may, in some cases, maintain an abusive relationship.

Foster carers may have a different perspective on family contact. They may consider family contact as not that beneficial for the behaviour and well-being of children and young people in their care, and instead see it as having a negative impact on the children's and young people's adjustment to the placement and the relationship they establish with the foster carers (Osborn \& Delfabbro, 2009). Hedin (2015) stresses the relevance of co-parenting strategies between foster carers and biological parents, with the support provided by socia workers being key. Furthermore, social workers on the study of Sen and McCormack (2011) highlight that the involvement of foster carers in contact arrangements can contribute significantly to their success.

Considering long-term foster care, children and young people who are in contact with their families of origin may experience loyalty conflict regarding the relationships they have with their families of origin and that they establish with their foster carers. Those children and young people who experience this conflict may have higher levels of emotional and behavioural problems, which can contribute negatively to placement stability (Leathers, 2003).

On the other hand, children and young people in care have reported that they wish to have more contact with their families of origin and that contact makes them happy. Moreover, they feel that they are mainly well adjusted to their placement and that they belong to that environment (Chapman, Wall, \& Barth, 2004). Nonetheless, the contact arrangements should be flexible taking into account the schedules of the children and young people and their wishes, which can change over time (Atwool, 2013).

Morrison, Mishna, Cook, and Aitken (2011) stress that social work team members and foster carers may have different perspectives about contact and that these perspectives may not reflect what children or young people feel. Considering the differences in perspectives, it is important to listen to the voice of children and young people in care and also to analyse the perspectives of the different other stakeholders.

Considering the complex range of factors that influence contact, authors such as Déprez and Wendland (2015) emphasize the need to conduct more research about the maintenance of contact between the child or young person and their family, its quality, and specifically about the circumstances in which family contact for children and young people may or may not be beneficial.
This paper offers a Portuguese perspective on some of the issues discussed in the section above relating to family contact in foster family care, reporting on the views of children, parents, foster carers, and social workers.

\section{I PORTUGUESE CHILD PROTECTION SYSTEM}

The Portuguese Law on the Protection of Children and Young People in Danger (Law 142/2015 of September 8th) favours the placement of the child in a family environment, foster care, especially for children up to the age of 6 years old. Despite this recent legal measure, there is still heavy reliance on residential placement for children looked after in Portugal.

Although 8,175 children and young people were in out-of-home care in 2016 in Portugal, only 261 of these were placed in foster care, with the remainder in residential care (Instituto da Segurança Social, 2017). Therefore, one of the children and young people's fundamental rights under the UN Convention on the Rights of the Child-living in a family environment-is largely compromised in practice.

In fact, in recent years, the protection system has seen a proportional increase, from $93.2 \%$ in 2009 to $96.8 \%$ in 2016 in the use of residential care, where 7,914 of the children and young people are currently placed (Instituto da Segurança Social, 2017). This scenario has no parallel in countries with an industrial or post-industrial model, with which Portugal shares greater cultural and social affinities (Courtney \& Iwaniec, 2009; Gilbert, Parton, \& Skivenes, 2011). It is true that there are other parts of Europe, including Greece, Spain, or even Germany, as well as Eastern Europe (Del Valle \& Bravo, 2013), with a high use of residential care, but nowhere has rates compared with Portugal.

The causes of resistance to deinstitutionalization might be associated with different factors. Historically, policy has given the Catholic Church and, later, the State the responsibility of caring for the most unprotected children. Currently, the network of children's homes covers the entire national territory and provides more than enough places for the placement of all children and young people in care. Since 2008, kinship care is no longer considered legally as a type of foster care, which has significantly contributed to the reduction of the proportion of children and young people in foster care. All these factors are combined with a social policy that has clearly disregarded, in the last decade, foster care successively postponing the investment in the organizational, human, and financial resources that are indispensable to its development.

On the other hand, several studies conducted recently in Portugal have shown the positive outcomes achieved by children and young people in foster care (Delgado et al., 2013) and the poor outcomes that characterize children in residential care (Oliveira, Fearon, Belsky, Fachada, \& Soares, 2014). Foster families are mostly located in the north of the country, with greater expression in the district of Porto, which probably results of the investment of the Social Services' team in foster care and its growing recognition in the local community.

Approximately two thirds of children and young people placed in foster care stay in contact with their families of origin (Delgado et al., 
2016). Considering this characteristic of the Portuguese foster care system, and the need for the children and young people to find balance in their relationships with their family of origin and their foster carers, our principal aim is to explore their experiences of contact, their views about it, and to complement this evidence with the perspectives of the other three actors: foster carers, parents, and social workers. We recognize that knowledge and understanding of a reality can only be developed through people's own actions, relationships, and by the social construct of meaning, this being the basis of the pragmatic theoretical perspective (Pring, 2007), therefore we have decided to start this research project by listening to the voices of children and young people rather than hearing their voices through the speech of other actors.

\section{3 | METHODS}

This study is the result of a project developed by InED, the Center for Research and Innovation in Education from the School of Education of the Polytechnic Institute of Porto, entitled "Contact in Foster Care: Patterns, Outcomes and Management Models." The general objective of the project is to investigate the results of contact between the child or young person in foster care and their family of origin, or the reasons for its non-existence or cessation. The main study that involved applying questionnaires to large samples of foster carers and supervising social workers has led to the following main conclusions: (a) the importance of including in foster carers' training a topic about relationship with birth parents; (b) the need to develop a specialized supervision process that closely monitors the context and progress of the visits on a regular basis; (c) and the need to adjust the visit plan to the actors involved, in order to promote their compliance with the visit schedule. For the purpose of this article, which presents the qualitative pilot study, we will focus our analysis on the perceptions of children and young people, social workers, birth parents, and foster carers in relation to contact.

\subsection{Samples and procedure}

The main project was designed to gather information, using similar questionnaires, from social workers, birth, and foster families related to all the 221 children and young people in foster care in the Porto district. This set of 221 children represented $59.1 \%$ of the total number of children and young people in foster care in Portugal (Instituto da Segurança Social, 2017). The 221 children and young people were born in 161 families and were looked after by 141 foster families. The sample included 97 girls (43.9\%) and 124 boys (56.1\%) with a mean age of 15.14 years $(S D=4.78)$.

From the sample of 221 children and young people, $66.5 \%$ had contact with their birth families: $38.5 \%$ had visits and other type of contacts (telephone, e-mail, social networks, post letters, phone messengers); $25.3 \%$ only visits; and $2.7 \%$ only other type of contacts. The visits were supervised by professionals in $4.5 \%$ of the cases.

For the purpose of the pilot study, 17 children who had contact with the family of origin were randomly selected to participate in focus groups, based on three criteria: gender, age group (6-9;
10-13; and 14 years old or more), and time length of placement (up to 1 year; between 1 and 3 years; more than 3 years). This implied that with 18 children, we could cover all criteria in terms of representation and gather a group acceptable to conduct three focus groups. However, one of the criteria combination result (male, between 10 and 13 years old, and up to 1 year in foster care) did not have any child meeting those criteria. Eventually, within this sample, and because four children missed the focus group session, it was possible to conduct focus groups with 13 children and young people. After this, interviews were conducted with their social workers (who supported the children or young people, their families of origin, and their foster carers), biological parents, and foster carers.

All procedures were approved by the Portuguese Social Services authorities, as well as by the ethics board of Polytechnic Institute of Porto. All participants signed consent forms and received detailed information about the study, such as their right to withdraw at any time. All focus groups and interviews provided opportunities for participants to share their views in a way that sought to minimize the likelihood of distress or discomfort. Specifically, with children and young people sensitive issues associated with precare experiences or reasons for entry to care were not raised. During the preparatory contact process to schedule the interview meetings, three families of origin withdrew their consent and dropped out of the study, and as a result, the final sample was reduced to a total of 10 cases.

We will describe the context of contact of the 10 children and young people, about whom we have data from all stakeholders. In each of those 10 cases, we interviewed the carers, professionals, and parents. These children were between 7 and 22 years of age, with a mean age of 11.6 years $(S D=4.84)$, and were evenly distributed by gender, with five females and five males. The young woman of 22 years has mental handicap, so she stays formally with her foster family after legally reaching adulthood. These children and young people had been in foster care for an average of three and a half years, with lengths of stay ranging between 2 months and 15 years.

The contact can take place in different places for different children and young people. The majority meet their family of origin in their home, although it can also take place in the home of the foster carers, or, for a minority of children and young people, it can take place in the offices of the fostering team. The contact takes place every week or every fortnight, and the mother is the family member most likely to be present, followed by the father, and siblings. Although the contact is promoted by the fostering team, in practice, foster carers are the ones that give more support for it to happen by helping with the logistics.

\section{2 | Data collection instruments and analysis procedure}

In order to gather the same type of information and to understand how the different stakeholders perceived the same issues, the script of the focus groups of the children and young people and the script of the interviews of the social workers, biological parents, and foster carers covered the same topics. The topics under analysis were description of the contact process, importance attributed to contact, and importance attributed to the foster care placement. 
Data were treated with confidentiality, maintaining the anonymity of participants. Real names are not used in this paper. The content analysis of the texts of the interviews and focus groups was done using MAXQDA 10.0 software, and the information was grouped into mutually exclusive thematic dimensions, which will be presented in the next section of the article.

\section{4 | FINDINGS}

The collected data are structured and presented in three parts, according to children's and young people's voices and experiences: children's and young people's relationships and attitudes during the placement, children's and young people's reaction during and after the visit, and difficulties reported by participants in relation to contact.

\subsection{Children and young people's relationships and attitudes during the placement}

What do the children and young people report about the foster placement, their own contact with family members, and the interactions between foster carers and birth family members?

Foster care is described as a genuine context of family life, where protection, a positive use of leisure time, social relations between peers, and a better scholar route are developed. The narratives underline the importance of visits at the time of separation and in daily life, away from parents and siblings. It also signals that children are aware of the way the relationship between their parents and the home is unfolding and how that relationship may worry them.

From the point of view of the youngest children who participated in the Focus Group (FG) 6-9 years (FG session 6-9 years), the relationships they maintained while in foster care are positive because they can play with the foster carers, because they have friends, and because they can be with their parents. Their contentment is evident in the testimony of Renato (7 years old), who wanted to stay with his foster carers until he got married at the age of 16 or 17.

In the case of Armando (17 years old) and his siblings, the foster carers' attitudes were decisive to keep the brothers united and to reduce, in this way, the negative impact of the removal: "my foster mother wanted to keep the three of us, but it wasn't possible. So she said, but I don't want them to be separated either ... because they grew up together, they're used to each other. Then, she talked with two friends of hers in order to take in my siblings. Therefore, we live apart, but are always together. Today I'm going to see one, another day to see the other ... so we don't lose contact and we are very strong." These comments underline the importance of the visits, the possibility of maintaining contact with their families, seeing their various members, and reducing the feeling of separation and longing.

The resilience of Joana (16 years old) emerges spontaneously when she said that "Nobody should be discarded [...]. My parents may not have much money, but they help everyone. We learn to live with other people." She recognized that being in foster care allows her to live out new experiences, to discover "the art of studying," and to have different achievements in school, because the foster carers care about her progress and encourage her to do better. There are several testimonies of the children and young people that took part in the focus groups that highlighted the changes for them associated with the foster care placement, in the field of health, at the behavioural level, and in relation to school attendance and results. Moreover, the children also mentioned that the placement increased the possibility of meeting new people and having friends, to have psychological counselling and the support to overcome some conflicts, and also having an overall sense of protection.

Armando said: "At the age of seventeen I have already finished the twelfth year in school, and in maturity, I speak for myself. But at seventeen I can have a conversation with my head and feet. And I feel that many people with my age can't. They change ideas very easily, and I don't, I have my opinions (...) It's life experiences that make us think."

Talking about contact with her mother, Francisca (12 years old) recognized that "For me, the beginning was the hardest part because I didn't want her (mother) to go away, I wanted her to stay longer, but now I'm used to it." The adaptability of Anabela (12 years old) in the face of disrupted relations with her parents is evident in this account: "It's more the homesickness's we feel, because the time passes by, and we don't feel it passing by, and then there are days that I can't understand, I can't get used to my parents having to leave, I can't imagine it, and I can't leave my parents alone, I like being with them a lot, quite a lot, and if I could I would also spend a lot of time with them. But at the beginning I also think that everyone starts to cry because they miss them, they think they will not see their parents, but in the end they realise they will always be seeing their parents, and be with them."

The relationship that their parents develop with the foster carers can worry some of the children and young people. For Renato (7 years old), the worst thing about being placed in foster care is the way that his father argues with the foster carer. Anabela (12 years old) said that "My father and my aunt (the foster carer) are always arguing on the phone, my father upsets my aunt. In my opinion my father doesn't do anything, my mother is still trying to solve problems with my aunt, and when it is possible she helps, when she can't she doesn't help."

One critical issue in this case was the name given to the relationship with the foster carer, as illustrated in this extract from an interview:

Question : "And your father ends up arguing on the phone with your aunt because your aunt would like him to visit you more often and he doesn't do it?"

Anabela - - "Yes, yes. And also, because we call the foster carers uncle and aunt and my father says not to call them like that."

\subsection{Children and young people's reaction during and after the visit}

In this part, we present the data about the immediate response to interactions, the reactions to visits and cancellations, and the longterm nature and consequences of contact. 
With regard to contact and more specifically to visits, one of the indicators to consider is how the child or young person feels and what reactions they manifest. Rui (7 years old) said that he likes visits. Carla (8 years old) said she would like her mother to come to see her more often and that visits are important because she misses her. António (7 years old), on the other hand, when asked about what he likes most about visits, said: "I'll say it! I like her love." Renato (7 years old) said: "sometimes, my two mothers [biological mother and foster mother] are very friendly, and are very close to me." But he also adds that "the visits could be a bit shorter." (FG session 6-9 years).

Francisca (12 years old) expressed her thoughts about visiting "it's important because once we leave our family of origin, I think it's also good to be with our parents for a while." Anabela (12 years old) said that "there are moments when it's hard to understand what I feel, I can't get used to see my parents go away, I can't see it and I can't leave my parents alone, I like to be with them a lot, quite a lot, and if I could I would also spend a lot of time with them." Marta (22 years old) even stated that she would like to go to court many times, in order to see her father more often:

Question : If you could change something, would you like to go to court more often?

Marta : "When we go to court, the parents have to go too ..."

Question : "Because in that situation they are forced to go there, aren't they?"

Marta : "Yes, they are."

Joana (16 years old) also likes the visits and said that the best part "is to be with my brothers, with my parents and with my cousins ...." Jaime's (14 years old) family of origin noted that "he shows a good reaction, and wants to be with us more time." Jaime said that he likes the visits because it is the way to be with his brother: "I am with my family, my brother and grandparents." (FG 14 years or +).

In the long term, there are some concerns raised in relation to the consequences of contact with, and visits from, the biological family, despite the mostly positive comments of children and young people. The professional that supports Joana (16 years old) considered that "it's a very beneficial time for her, but afterwards we all come to the conclusion that the child can't manage this euphoria and happiness very well, because she ends up being confused about whether it was a positive or not ... she has a high expectation of returning home, and we have worked with her." The situation of Anabela (12 years old) was similar. In such cases, the children enjoy the contact so much then they must wonder why they cannot actually be at home.

When evaluating the moment before contact, it is important to note that, in the cases under analysis, the reactions manifested by each child or young person are perceived differently by the participants. In particular, foster carers are divided when recording reactions of joy, indifference, or anxiety; the majority of social workers identified anxiety as the dominant reaction; and the families of origin only reported reactions of joy. It can be seen that the families of origin have a more positive perspective than the social workers and the carers.

The perspectives of the actors involved in relation to the reactions of the children or young people after the visit revealed once again considerable disagreement. The foster carers identified different reactions, which vary between agitation, joy, indifference, and sadness; social workers, on the other hand, identified reactions of joy or anguish, whereas the families of origin only mentioned sadness. As with the reactions before the visit, it seems that the families of origin have a more positive view of the visits.

\subsection{Difficulties in relation to the frequency of contact}

The difficulties associated with contact between the child or young person and the family of origin are perceived with different intensities by the participants (FG 6-9 years). Rui (7 years old) stated precisely that "when she comes it is cool, when she doesn't come ...." Carla (8 years old) stated that she would like her mother to visit her more often, "but she can't," and António (7 years old) likes her mother because "she gives me love, treats me well, and gives me gifts." On the other hand, Carla said she did not do anything with her father and mother on the last visit. Renato (7 years old), when asked about what he would like to do at his parents' house, said simply that he did not like to do anything.

In the FG 10-13 years, Francisca (12 years old) said: "I would like my mother to spend more time with us, to compensate for the times that she didn't come," and he added: "She sometimes stays half an hour and then she has to leave." On the other hand, for Anabela (12 years old), $1 \mathrm{hr}$ every fortnight is enough. Therefore, some of the children and young people would like more time with the family, but for others, the time available is sufficient and they would not like to extend it.

Armando acknowledged (17 years old): "I miss my father very much." Age and experience have enabled him to develop contact management processes with his mother: "I gave my mother several opportunities. She explained what she had to explain, and she didn't give it that much relevance. But when people don't know how to enjoy it, it's better to let the things go on." And he underlined: "She had the possibility of visiting me at home. My mother [the carer] never closed the door, she is always available to receive her whenever she wants. It was she who gave up visiting me. Therefore, I guess the visit wasn't that important to her, and that's it." Regarding the relationship with his father, he said: "I have never lost contact, I'm proud of that."

Concerning the other actors, the type of difficulties listed varies substantially according to each group of participants. Families of origin considered the lack of money to pay for travel costs as the main difficulty, which is also related to the frequency of the trips. One mother reported the difficulty in bearing the costs associated with travel: "I am unemployed, attending training (...) It's difficult to pay for transport, but I never missed a visit; from February until now, I have always come." This difficulty is reaffirmed in another interview, when it is stated "we only have economic difficulties, because of transport." Another mother simply stated: "It's far away; I take 45 minutes to walk there" (she speaks of her difficulties walking; Table 1).

Social workers mostly reported relationship difficulties with the families of origin along with logistics of the visit. As an example: "there are no difficulties, it's very peaceful. It seems this mother doesn't want anything, Perhaps the greatest difficulty is the passivity involved." In another case, the professional highlighted aggressiveness in terms of discourse in the mother-child relationship. Logistical questions also 
TABLE 1 Main difficulty stated at the contact level

\begin{tabular}{|c|c|c|c|}
\hline Main difficulties & Family of origin & Professional & Foster carer \\
\hline Relation with family of origin & 0 & 4 & 4 \\
\hline Relation with foster carer & 1 & 0 & 0 \\
\hline Child's reaction & 1 & 0 & 1 \\
\hline Child's health & 0 & 0 & 1 \\
\hline Money & 4 & 2 & 0 \\
\hline Logistic & 1 & 3 & 0 \\
\hline
\end{tabular}

Source: self-reported.

arise, for example: "during bad weather, the mother would need to have a car, instead of having a motorcycle, and because of that she only visits her child when it doesn't rain. When it rains, it's a restriction and she can't come." This problem can be resolved with a good communication between the parties involved: "the last two visits were weekly, because the mother couldn't come when it was raining, so she didn't see her child for two weeks, but then saw her for two consecutive weeks."

The reports of the foster carers focused on the issues related to the families of origin. In one case, a foster carer said that "my greatest difficulties are the same as those of António. Will they come or not? Will they appear or not? Will I have to have another conversation with António? Will I have to call again and say no one showed up? These are my greatest difficulties and doubts." Failing a visit has a negative impact on the foster child because, according to the same foster carer, "if you had a child you wouldn't like to see that he was there waiting for something he thinks is so dear to him, because he loves his mother, and then that person fails him. This is complicated."

Detachment is mentioned in another case: "the mother should ask her children more questions, be more interested in what goes on in their lives. It isn't only what is apparent, she could sometimes go deeper into it ..." a view reinforced in the following statement: "He also liked his mother to be different at times. I think he would like me to be his mother, because he loved living with his mother, but he imagined a mother who isn't really his mother. And I notice that in the boy, he has an adoration for his mother. When his mother leaves, even when he sees just her arm, he continues to say goodbye. And so, that's complicated, I don't know, I don't know."

\section{5 | DISCUSSION AND CONCLUSIONS}

Children and young people in the focus groups expressed their views on contact and on the difficulties that were associated with it. These are intensely emotional experiences described with feelings of joy and loss, and longing and sadness, for not being able to spend more time with their families. In some cases, the visits were highly desired but considered to be scarce and short. In other situations, the children and young people were satisfied with the existing punctual contact or had created coping mechanisms regarding the disinterest of their parents. Also evident is the distinction they make about the nature of the contact they wish to maintain or deepen with each member of the family.
As pointed out by Triseliotis (2010), when contact is experienced as positive, it contributes constructively to the children development; furthermore, Chapman et al. (2004) mentioned that positive contact will also impact on the adjustment to their placement and to feelings of belonging to both set of carers. In this sample, most of children and young people stressed that they consider that they have consider important and good to be in contact with their parents, and that they were well integrated in foster care, seeing this experience as mostly positive. Apart from this, some children expressed how much they missed their parents, however, the fact they had contact allowed them to deal with the separation from the biological parents.

Difficulties in the relationship between biological parents and foster carers were affecting some of children and young people in care, which makes the relevance of foster carers and biological parents collaborating and supporting each other, as suggested by and Sen and McCormack (2011). In these situations, the support of the social services can also be crucial (HÖjer, 2011; Sen \& Broadhurst, 2011).

According to Hedin (2015), foster carers and biological parents ideally should be able to co-parent and to work together towards the well-being of the child. By looking at the perspectives of foster carers, biological parents, and social workers, on the reactions of the children and young people before and after the visit, it is evident that they have different views on the same reality. The same happens regarding their views on the difficulties of contact. It is interesting to note that social workers are the actors who perceive fewer difficulties at contact level, which can be explained by the fact that normally they are not present in the visit. Another explanation can be found in the fact that social workers are aware of various contact situations in foster care, especially in situations where visits are complex. This wider perspective may lead to their underestimating the difficulties experienced by foster carers and families of origin in these specific cases, which we are presumably less complicated than others.

The data reflect the need for foster carers and biological families to cooperate and to avoid conflict, as Osborn and Delfabbro (2009) found in their study. Social services can contribute significantly, by working with the biological parents at the level of the contact monitoring, financial support for them to be able to attend the visit, and especially, socioeducational intervention aimed the recovery of parental skills. This support needs to also be targeted at the relationship between families of origin and foster carers, in order to reduce communication difficulties.

In the current context, the scarce number of active foster carers in Portugal makes it difficult to choose a placement that is close to the family of origin's address, assuming that such proximity is not 
considered unsuitable by the fostering agency. This difficulty can only be gradually overcome by recruitment campaigns that can increase the number of foster carers, ensuring that they exist in the different districts and regions of the national territory, and are not only located, as now, only in certain districts of the north of the country.

This is a study based on only 10 children and young people; therefore, the sample size is a clear limitation and does not allow the extrapolation of the findings to the population. Nonetheless, the study design serves to highlight the voice and experiences of children and young people in care, to offer a holistic overview based on the views of the different stakeholders, and to analyse key aspects of contact. For instance, the present study indicates that in this group of children, contact does not influence the way they evaluate family care, the experience they describe living in care is not dependent on frequency or content of the visits with their family of origin.

Intervention in this context must be more focussed on the points of view of the children and young people and seek to understand and critically interpret their opinions about their present and future life in foster care, informing and involving them in the decision-making processes during the placement, according to their age, experience, and maturity. It was possible to show that children and young people express positive opinions regarding the relations that they maintain with their foster carers and fears about how their parents relate to their foster carers. The collected testimonies underline that children and young people are able to manage difficult experiences, gradually seeking to adjust and conserve as much as possible the "better of two worlds." It can be concluded that the relationship with their parents is difficult, when parents do not make the planned visits or when they shorten their visit, without justifying reasons.

The evidence gathered points to the need to improve the communication system and the interaction between children and young people, social workers, foster carers, and families of origin. There is an urgent need to clarify the role of each actor in this complex web of relationships in order to promote the well-being and guarantee the effective protection and safety of the child or young person and to allow an adequate assessment of the continuity of the contact and of the placement.

\section{ORCID}

Paulo Delgado (1) http://orcid.org/0000-0001-6977-8214

\section{REFERENCES}

Atwool, N. (2013). Birth family contact for children in care: How much? How often? Who with? Child Care in Practice, 19(2), 181-198.

Carvalho, J. M. S., \& Delgado, P. (2014). Contact in foster care: Bridge or collision between two worlds? Journal of Applied Research on Children: Informing Policy for Children at Risk, 5(1). Article 10. Available at http://digitalcommons.library.tmc.edu/childrenatrisk/vol5/iss1/10

Chapman, M., Wall, A., \& Barth, R. P. (2004). Children's voices: The perceptions of children in foster care. American Journal of Orthopsychiatry, 74(3), 293-304. https://doi.org/10.1037/0002-9432.74.3.293

Coakley, T. (2013). The influence of father involvement on child welfare permanency outcomes: A secondary data analysis. Children and Youth Services Review, 35(1), 174-182. https://doi.org/10.1016/j. childyouth.2012.09.023
Courtney, M., \& Iwaniec, D. (2009). Residential care of children. New York: Oxford University Press.

Del Valle, J., \& Bravo, A. (2013). Current trends, figures and challenges in out of home child are: An international comparative analysis. Psychosocial Intervention., 22, 251-257. https://doi.org/10.5093/ in2013a28

Delgado, P. (coord), Bertão, A. Timóteo, I. Carvalho, J. Sampaio, R. Sousa, A. et al. (2013). Acolhimento familiar de crianças. Evidências do presente, desafios para o futuro. Livpsic, Porto.

Delgado, P. (Coord.), Sousa, A., Bertão, A., Moreiras, D., Timóteo, I., Oliveira, J., et al. (2016). O contacto no acolhimento familiar. O que pensam as crianças, as famílias e os profissionais. Mais Leitura, Porto.

Déprez, A., \& Wendland, J. (2015). La visite parentale chez l'enfant placé, une revue de la littérature. Annales Médico-Psychologiques, 173(6), 494-498. https://doi.org/10.1016/j.amp.2013.07.009

Fawley-King, K., Trask, E. V., Zhang, J., \& Aarons, G. A. (2017). The impact of changing neighborhoods, switching schools, and experiencing relationship disruption on children's adjustment to a new placement in foster care. Child Abuse \& Neglect, 63, 141-150. https://doi.org/ 10.1016/j.chiabu.2016.11.016

Gilbert, N., Parton, N., \& Skivenes, M. (2011). Child protection systems. New York: Oxford University Press.

Hedin, L. (2015). Good relations between foster parents and birth parents: A Swedish study of practices promoting successful cooperation in everyday life. Child Care in Practice, 21(2), 177-191.

Höjer, I. (2011). Parents with children in foster care-How do they perceive their contact with social workers? Practice: Social Work in Action, 23(2), 111-123.

Instituto da Segurança Social (2017). Relatório Casa 2016-Caracterização Anual da Situação de Acolhimento das Crianças e Jovens. Lisboa: Instituto da Segurança Social.

Leathers, S. J. (2003). Parental visiting, conflicting allegiances, and emotional and behavioral problems among foster children. Family Relations, 52(1), 53-63. https://doi.org/10.1111/j.1741-3729.2003.00053.x

McWey, L. (2000). I promise to act better if you let me see my family: Attachment theory and foster care visitation. Journal of Family Social Work, 5(1), 91-106. https://doi.org/10.1300/J039v05n01_07

McWey, L., Acock, A., \& Porter, B. (2010). The impact of continued contact with biological parents upon the mental health of children in foster care. Children and Youth Services Review, 32(10), 1338-1345. https:// doi.org/10.1016/j.childyouth.2010.05.003

Morrison, J., Mishna, F., Cook, C., \& Aitken, G. (2011). Access visits: Perceptions of child protection workers, foster parents and children who are Crown wards. Children and Youth Services Review, 33(9), 1476-1482. https://doi.org/10.1016/j.childyouth.2011.03.011

Moyers, S., Farmer, E., \& Lipscombe, J. (2006). Contact with family members and its impact on adolescents and their foster placements. The British Journal of Social Work, 36(4), 541-559. https://doi.org/ 10.1093/bjsw/bch270

Oliveira, P., Fearon, R., Belsky, J., Fachada, I., \& Soares, I. (2014). Quality of institutional care and early childhood development. International Journal of Behavioral Development, 1-10. https://doi.org/10.1177/ 0165025414552302

Osborn, A., \& Delfabbro, P. (2009). Foster carers perceptions of the effects of parental contact upon children's psychosocial wellbeing in long-term foster care. Communities, Children and Families Australia, $4(2), 18-33$.

Pring, R. (2007). John Dewey: A philosopher of education 21st century. London: Continuum.

Sen, R., \& Broadhurst, K. (2011). Contact between children in out-of-home placements and their family and friends networks: A research review. Child \& Family Social Work, 16(3), 298-309. https://doi.org/10.1111/ j.1365-2206.2010.00741.x 
Sen, R., \& McCormack, J. (2011). Foster carers' involvement in contact: Other professionals' views. Practice: Social Work in Action, 23(5), 279-292.

Triseliotis, J. (2010). Contact between looked after children and their parents: A level playing field. Adoption and Fostering, 34(3), 59-66.

Vanderfaeillie, J., Van Holen, F., \& Coussens, S. (2008). Why do foster care placements break down? A study into the factors influencing foster care placement breakdown in Flanders. International Journal of Child and Family Welfare, 11(2-3), 77-87.
How to cite this article: Delgado P, Pinto VS, Carvalho JMS, Gilligan R. Family contact in foster care in Portugal. The views of children in foster care and other key actors. Child \& Family Social Work. 2018;1-8. https://doi.org/10.1111/cfs.12586 